\title{
Nuevos datos inéditos sobre Velázquez
}

\author{
Esteban Ángel Cotillo Torrejón \\ Doctorado en Historia del Arte. UNED
}

\begin{abstract}
RESUMEN. ABSTRACT.
Durante el proceso de investigación realizado sobre la Real Capilla de San Isidro, tuvimos ocasión de hallar algunos datos que permanecían inéditos, datos que abrían nuevas expectativas en torno a la figura de Velázquez. Dado el interés que poseen para conocer, aún más si cabe, las múltiples facetas del pintor sevillano, nos han movido a tratar de aclarar y situar en su contexto histórico las nuevas noticias que aportamos en este artículo.

During the historical investigations carried out on the Royal Chapel of San Isidro, there were some previously unpublished documents uncovered. Contained within these documents gave rise to new possibilities and expectations surrounding the artist Velázquez. Given the information they contain gives eve more understanding to the multiple facets of the painting "Sevillano". With this new documentation we are much better able to clarify and establish the true historical value.
\end{abstract}

Iniciamos este artículo presentando el documento en cuestión (ver Fig. 2), se trata de una libranza efectuada el 20 de Septiembre de 1659, a favor del Aposentador Mayor Diego Velázquez, cuya trascripción es la que sigue:

\section{"Diego Velasquez, madera de palaçio.}

En 20 de dicho mes de setienbre se libraron a Diego Velasquez, aposentador mayor de palacio, 3.800 reales, por los mismos que con el se conçerto la madera y clavaçon de los andamios que se pusieron para pintar al fresco el salon de palaçio, y la madera de la escalera por donde se sube al dicho andamio por la plaça de pa- 
laçio, que se a comprado para haçer las cimbras de los arcos torales y andamios para la fabrica de dicha capilla. 3.800.»1

Debemos, ante la vista de tal documento, aclarar al menos dos aspectos: el primero, y quizás más importante, el papel jugado por Velázquez en esta operación, y el segundo de ellos, tratar de dilucidar que sala de Palacio había sido pintada al fresco en esa época.

\section{1. ...DIEGO VELÁZQUEZ, APOSENTADOR MAYOR DE PALACIO}

En 6 de Enero de 1643, el pintor real Diego de Silva Velázquez fue nombrado por su rey, Felipe IV, Ayuda de Cámara²; para unos meses después recibir un nuevo nombramiento:

"A Diego Velázquez, mi Ayuda de Cámara, he encargado que, debajo de la mano del Marqués de Malpica, asista a la Superintendencia de las obras particulares que yo señalare, dándole setenta ducados al mes de gajes en la forma que se dieron a Francisco Preves, y en esta conformidad se le dará el despacho necesario para que se lo paguen según y como se suelen los que son de este género.

En Madrid a 9 de Junio de 1643. ${ }^{3}$

Tal nombramiento permitía a Velázquez relacionarse, de una manera directa, con los maestros y oficiales que trabajaban en las obras reales. Gracias a ello entablará relación con el Maestro Mayor de las mismas, Juan Gómez de Mora, y con el que será nombrado en 14 de Junio de 1645 Ayuda de Trazador Mayor, José de Villa Real ${ }^{4}$. De esta manera Velázquez podía tratar con los maestros de otros y oficios que trabajaban en la villa y corte, y que de una u otra manera estaban relacionados con las obras que se llevaban a cabo en el Alcázar Real.

Es evidente que Felipe IV tenía en gran estima a su pintor de cámara, no sólo existía un afecto personal, también reconocía su mérito artístico y su capacidad de trabajo. Por ello, y en conexión con su cargo de asistente de la superintendencia de las obras reales, se le nombra, el 22 de Enero de 1647, Veedor de las obras de la Pieza Ochavada del Alcázar ${ }^{5}$. Las obras de tal pieza estaban casi concluidas,

1 Datta de las cantidades... Archivo Histórico Municipal de Madrid. Legajo 2-284-8/4. ${ }^{a}, f^{\circ} 93 \mathrm{v}$.

a Archivo del Palacio Real de Madrid, Caja 1084. Varia Velazqueña, Ministerio de Educación Nacional, Madrid, 1960. t. II, pág. 252.

3 Ídem., pág. 253.

4 TOVAR MARTIN, VIRGINIA: Arquitectos Madrileños de la segunda mitad del siglo XVII, Instituto de Estudios Madrileños, C. S. I. C. Madrid, 1975. pág. 123.

5 Archivo del Palacio ReAl de Madrid: Cédulas Reales, t. XIV, fo 148. Varia Velazqueña, Ministerio de Educación Nacional, Madrid, 1960, t. Il, pág. 259. 


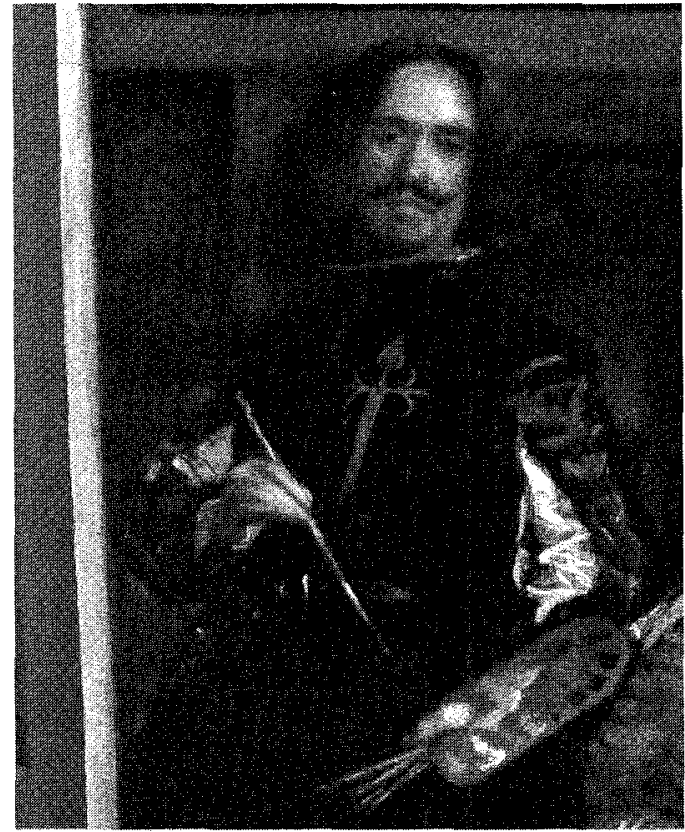

Fig. 1. Diego de Silva Velázquez.

Las Meninas, detalle de su autorretrato (1656). Museo del Prado, Madrid.

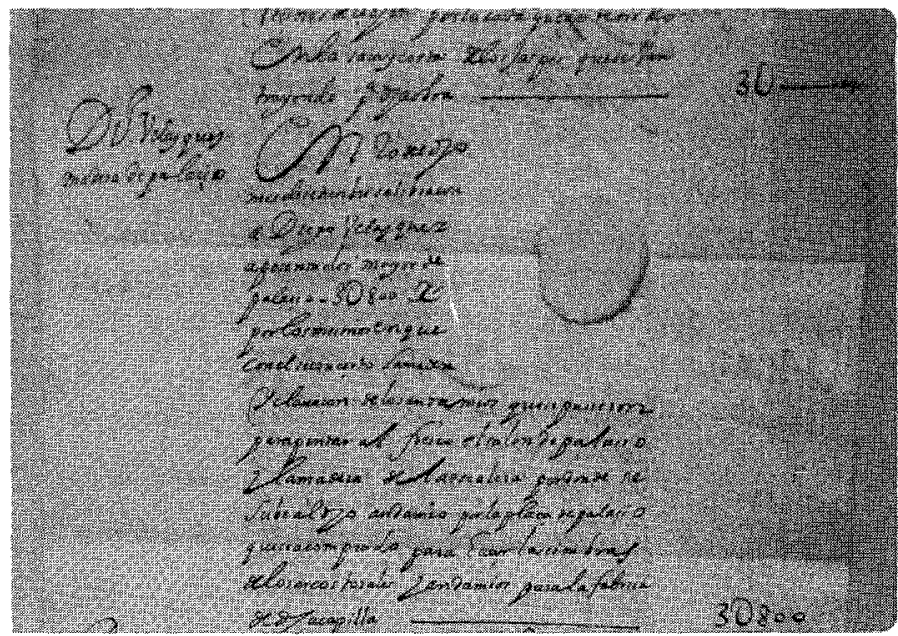

Fig. 2. Datta de las cantidades... Libranza a Velázquez. Legajo 2-284-8/4a, $f^{\circ} 93 \mathrm{~V}$.

Archivo Histórico Municipal, Madrid. 
por lo que el trabajo debía quedar reducido a labores administrativas, y posteriormente al de su ornamentación, como acertadamente señala Tovar Martín ${ }^{6}$. De hecho, en una Orden Real se dice que además de despachar y firmar las libranzas aplicadas a estas obras del Ochavo, debía " tomar razón de todas las cantidades que antes de ahora se hubieren librado para ella... »7.

Velázquez viajará a Italia el 16 de Noviembre de 1648, fecha en que sale de la corte con destino a Málaga donde habría de embarcarse; su permanencia en Italia se dilató hasta el año de 1651, llegando a la corte a finales de Mayo o principios de Junio, según se desprende de la correspondencia mantenida por Felipe IV con el Duque del Infantado ${ }^{8}$.

Tras su regreso será propuesto para el cargo de Aposentador, ya que el puesto quedaba vacante al nombrarse a Pedro de Torres Secretario de la Cámara. Junto a Velázquez se proponían los nombres de: Gaspar de Fuensalida, Francisco de Rojas, Simón Rodríguez, Alonso Carbonel y José Nieto; el rey decidirá, el 16 de Febrero de 1652, que sea Velázquez el nuevo Aposentador Mayor, jurando su cargo el 8 de Marzo 9 .

Ya tenemos al pintor ostentando el cargo de Aposentador Mayor de Palacio, el cual llevaba aparejado multitud de funciones ${ }^{10}$, ocupaciones que, unidas a las concernientes al resto de cargos que ostentaba, le restarían tiempo para su producción pictórica; entre estas labores estaría la venta del andamiaje aquí señalado.

La última gran merced que Felipe IV concederá a su pintor de cámara aparece en la Real Orden de fecha 27 de Noviembre de 1659, por ella se ordena el despacho del título de Caballero de la Orden de Santiago a D. Diego de Silva Velázquez ${ }^{11}$. La relación completa de los cargos cortesanos de Velázquez aparece en la portada de una Memoria fechada en 1658, editada por un tal Iván de Alfaro, y que se ha demostrado es apócrifa (ver Fig. 3).

Retomando nuestra línea argumental podremos aseverar que, en todo caso, es evidente que entre el Maestro Mayor de la fábrica de la Capilla de San Isidro y Velázquez, existía algún conocimiento y relación que vendrían dados por estar ambos relacionados con las obras del Real Alcázar. Tengamos presente que José de Villa

6 Tovar Martín, Virginia: «El pintor Velázquez ¿decorador y arquitecto?», Revista de Arte, Geografía e Historia, n. ${ }^{\circ}$ 2, Madrid, 1999, pág. 273.

7 ARChivo del Palacio ReAl de Madrid: Varia Velazqueña, Ministerio de Educación Nacional, Madrid, 1960, t. II, pág. 260.

${ }^{8}$ Archivo Histórico Nacional: Osuna, leg. 1983. Varia Velazqueña. Ministerio de Educación Nacional, Madrid, 1960, t. II, págs. 275 y 276.

9 Archivo del Palacio Real de Madrid: Felipe $N$. Casa, leg. 79, n. ${ }^{\circ} 282$, caja 1084-1089.

Varia Velazqueña. Ministerio de Educación Nacional, Madrid, 1960, t. II, pág. 280.

10 Ídem., pág. 498 y ss.

11 ARchivo Histórico Nacional: Informaciones de las calidades de Diego de Silva Velázquez. Varia Velazqueña. Ministerio de Educación Nacional, Madrid, 1960, t. II, pág. 377. 


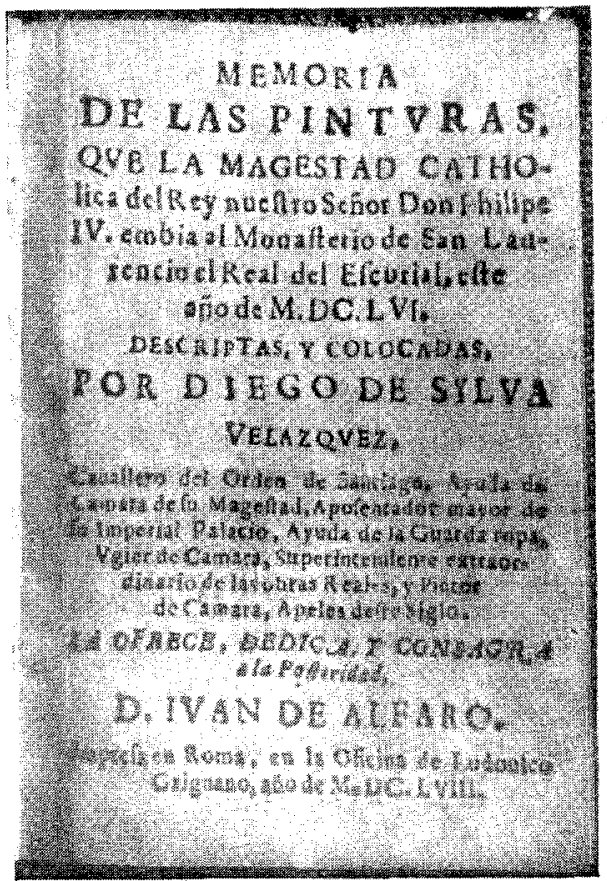

Fig. 3. Apócrifo. Memoria de las pinturas... Real Academia Española, Madrid.

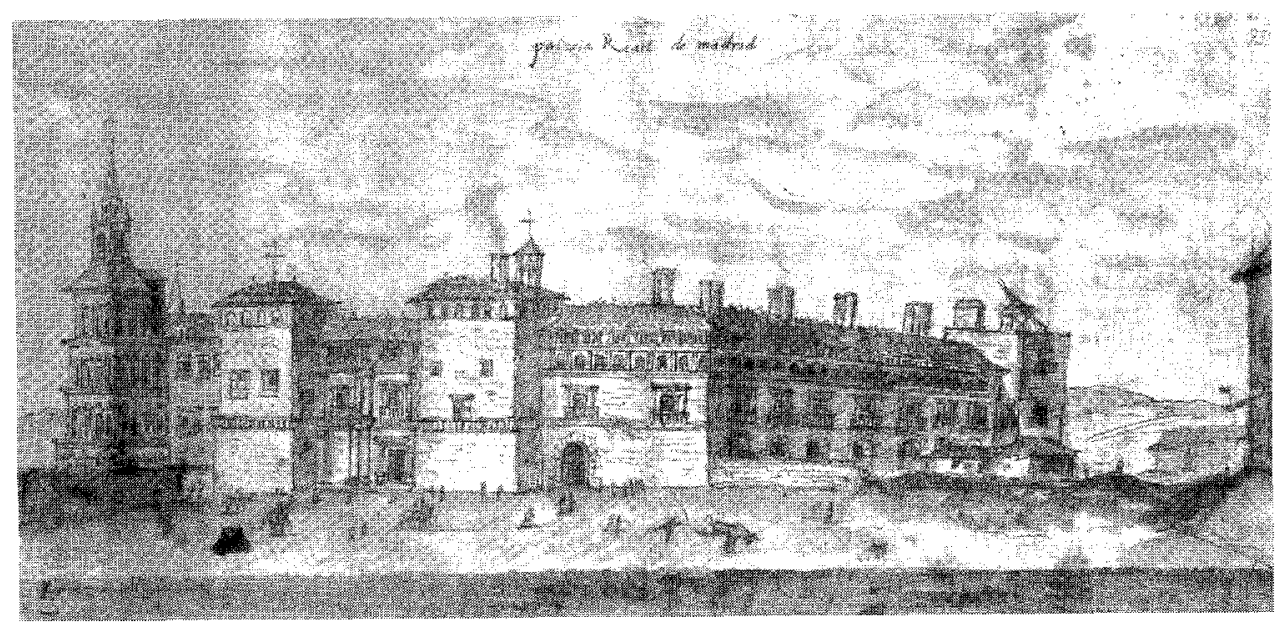

Fig. 4. Antón Van der Wyngaerde. Alcázar Real de Madrid, hacia 1569. Viena 73. Biblioteca Nacional, Viena. 
Real, maestro mayor de la fábrica de la Capilla de San Isidro, conocia a Velázquez de antiguo, recordemos que el discípulo de Juan Gómez de Mora había sido nombrado en 1645 Ayuda de Trazador Mayor cuando Velázquez tenía a su cargo la asistencia en las obras del Ochavo. En 1649, y tras la muerte de Juan Gómez de Mora, se otorgará a Villa Real el cargo de Maestro Mayor de las Obras de la Villa, nombramiento que sin duda hubo de conocer el Aposentador Mayor; será en 1654 cuando José de Villa Real reciba la merced real de ser el nuevo Aparejador Mayor de las Obras del Alcázar ${ }^{12}$. Por lo tanto, es patente que, al menos, existiría un trato personal y profesional entre Velázquez y Villa Real cuando se iniciaron las obras de la Capilla de San Isidro en 1657; ello habría permitido la compra de los andamios para reutilizarlos en esta fábrica.

En cuanto a las obras palaciales que se citan, estarían dentro de las que remodelaron el vetusto edificio durante el siglo XVII, adecuándolo a los gustos y necesidades de la corte, como a continuación veremos.

\section{2. ... PARA PINTAR AL FRESCO EL SALON DE PALAÇIO, Y LA MADERA DE LA ESCALERA POR DONDE SE SUBE AL DICHO ANDAMIO POR LA PLAÇA DE PALAÇIO.}

Para dilucidar esta cuestión debemos situarnos en el Madrid de mediados del siglo XVII, y aún antes, ya que los datos a los que nos debemos atener tratan de la remodelación del Real Alcázar de Madrid.

Ya en el siglo Xvı habían comenzado los trabajos para adaptar a las nuevas necesidades el medieval e irregular edificio, de hacia 1569 tenemos una imagen espléndida del Alcázar de Madrid (ver Fig. 4), obra de Wyngaerde. En ella vemos, en su extremo suroccidental, levantada la Torre Dorada que remató en 1568 Gaspar de la Vega, mientras que en el extremo noreste se trabajaba aún en la Torre de la Reina; en cuanto a la fachada sur, hallamos remozadas y remodeladas la Torre del Homenaje y la del Bastimento. A pesar de los trabajos ordenados por Felipe II, el Alcázar aún se nos presenta como una mole de escasa coherencia arquitectónica, hacia el exterior, y aún a falta de una decoración interior a tono con la dinastía que representaba y habitaba sus muros.

Sin embargo, los trabajos que nos importan se iniciaron en 1612, cuando Juan Gómez de Mora tomó a su cargo las obras que debían proseguir con la remodelación y modernización del edificio, adaptándola a una vida cortesana cada

12 José María de Azcarate: Datos para las biografias de los arquitectos de la corte de Felipe IV. Revista de la Universidad de Madrid,1962. pág. 532. 
vez más intensa ${ }^{13}$, estamos en el reinado de Felipe III, que morirá en 1621, sin haber visto concluidos sus proyectos.

Con anterioridad, Felipe II ordenó la construcción de una galería que permitiese a la corte presenciar las fiestas y espectáculos que tenían lugar en la Plaza de Palacio, de ello tenemos constancia gráfica, se trata de un dibujo de Jehan de l'Hermite, en el que se distingue la tal galería, que se iniciaba en la Torre Dorada y concluía delante de la Torre del Homenaje (ver Fig. 5).

Volviendo a Gómez de Mora a él se debe, como Maestro Mayor de las Obras Reales, la construcción de la fachada meridional (ver Fig. 6), iniciada en tiempos de Felipe III y concluida ya en época del rey Felipe IV, a la que dotaba de una articulación coherente, además de proporcionar al Palacio de una sobria y solemne fachada que realzaba la importancia de su plaza meridional como espacio ceremonial. Para lograr este objetivo, Gómez de Mora, levantó una fachada-telón que ocultaba la retranqueada del siglo XVI, encajonada entre las dos viejas torres medievales, tal y como podemos observar en el dibujo de Wyngaerde. Ahora, al levantarse la fachada nueva, quedaban espacios que permitían una reestructuración, dentro de las funciones palaciegas, de los nuevos habitáculos surgidos, y que provocaban la remodelación de otros ámbitos. Serán estos los que quedaban entre la nueva fachada y las viejas construcciones, en los que intervendrá también Gómez de Mora.

En la Biblioteca Vaticana se guardan dos plantas trazadas por Juan Gómez de Mora (ver Fig. 7), fechadas en 15 de Julio de 1626, donde se nos presenta la nueva disposición palacial, con la nueva fachada y las salas incorporadas, además se puede ver como las torres medievales quedan incluidas dentro del edificio, siendo transformados sus interiores, adaptados a las nuevas funciones a que se destinaban.

En las trazas correspondientes a la Planta Alta podemos identificar, de izquierda a derecha: la Torre Dorada o del Despacho (15), la Torre del Homenaje (86), que ha quedado convertida en la que se conocerá como Sala Ochavada; la Torre del Bastimento (46) que igualmente será reutilizada; y cerrando la fachada, la Torre de la Reina. También surgen nuevos salones, construidos entre los espacios que, entre torre y torre, se han ganado a la plaza con la construcción de la nueva fachada, el más destacado será el central, conocido como Salón Nuevo o Salón de los Espejos (26); y que aparece flanqueado por otros dos, más amplios, los conocidos como Galería del Rey (13) y Galería de la Reina (45). Con esta nueva disposición, Gómez de Mora realizó un planteamiento general de la fachada meridional, no ya sólo en cuanto a la distribución de la propia fachada, sino estructurando los espacios internos, incorporando a su proyecto la fábrica anterior

13 VARIOS AUTORES: Juan Gómez de Mora (1586-1648), Ayuntamiento de Madrid, Madrid, 1986. pág. 42. 


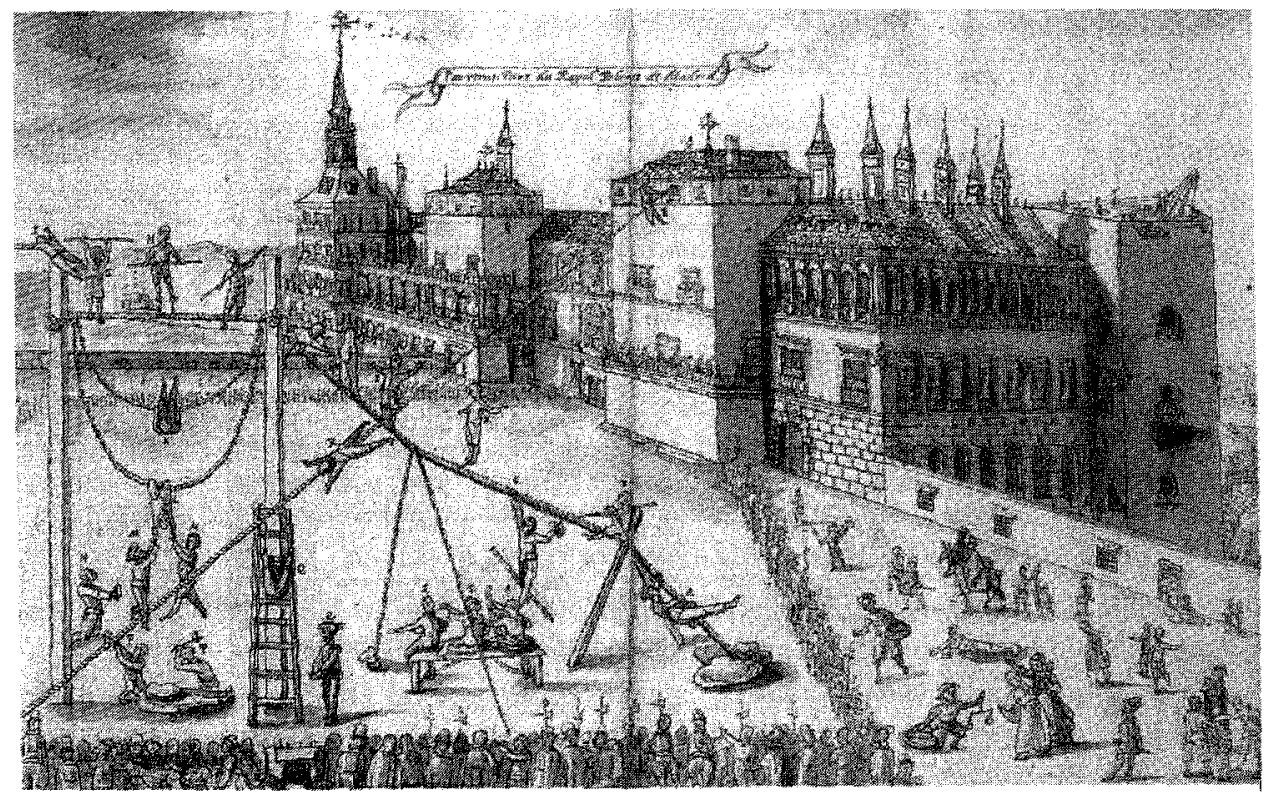

Fig. 5. Jehan de L'Hermite. Vista del Alcázar de Madrid con volatineros, 1596. Palacio Real, Bruselas.

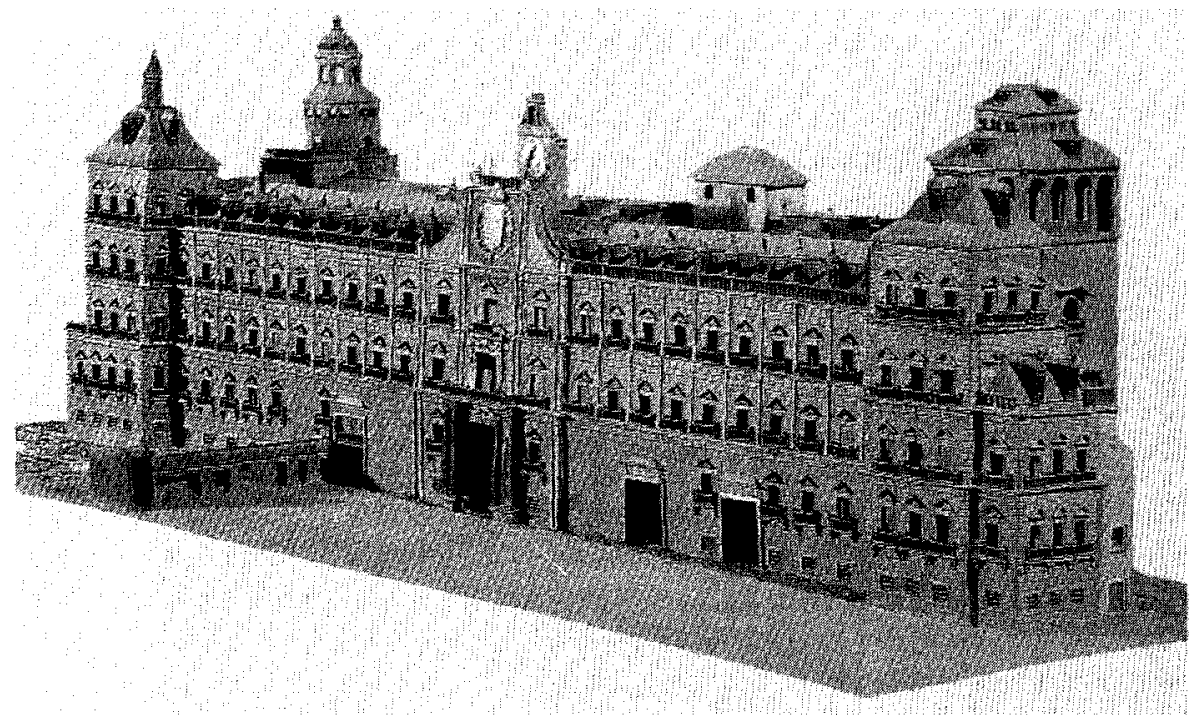

Fig. 6. Maqueta de la fachada del Alcázar de Madrid. Museo Municipal. 

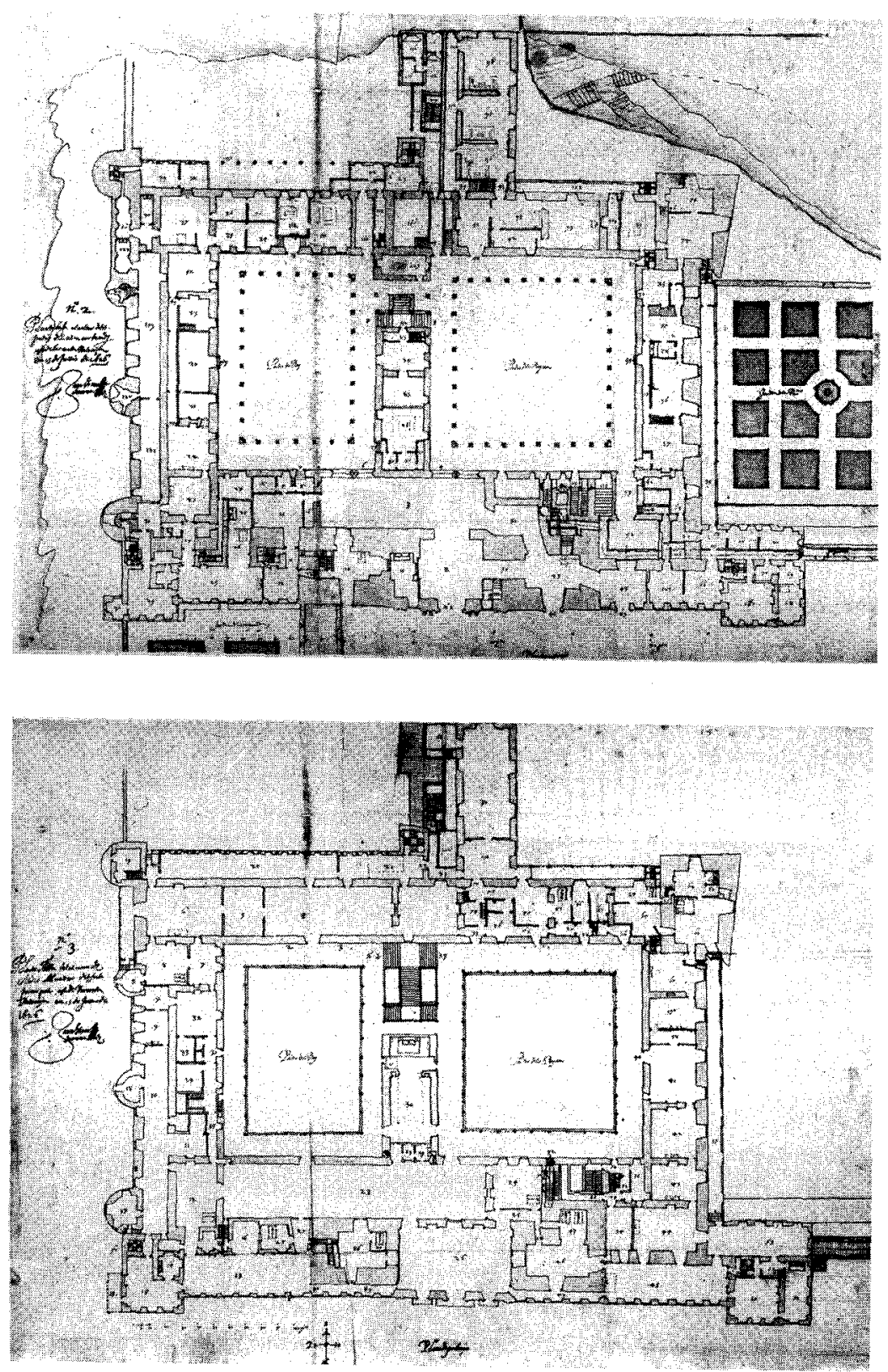

Fig. 7. Juan Gómez de Mora, 1626.

Arriba: Planta Baja del Alcázar. Debajo: Planta Alta.

Biblioteca Vaticana. 
e integrando sus elementos arquitectónicos, planteando un proceso integral de los viejos y los nuevos espacios.

Tengamos presente que aún se trabajaba en la Sala Ochavada en 1647, y que el Maestro Mayor de las Obras Reales, moría el 22 de Febrero de 1648, sin haber culminado su labor en el Alcázar, sucediéndole en el cargo Alonso de Carbonel. Aún quedaba mucho trabajo por realizar en los salones y estancias palaciales. El Salón Grande o de los Espejos, basaba su decoración en los grandes lienzos de Tiziano, Rubens y Velázquez que entre otros cubrían sus paredes, además le adornaban los famosos espejos con marcos de bronce de los que tomaba su apelativo, y bajo éstos se situaban grandes mesas sustentadas por leones de bronce que habían sido traídos de Italia por Velázquez ${ }^{14}$.

Todo el conjunto se había conformado con la finalidad de mitificar y ensalzar a la Corona Española. El regio salón se engalanaba con un zócalo de ricos mármoles, que se extendían también en las embocaduras de ventanas y puertas, por ello no es de extrañar que, para completar tal magnificencia decorativa, se pensase en cubrir sus bóvedas de pinturas al fresco. Y es aquí donde vemos, la mano del Aposentador Real.

En 1658 llegaron a Madrid, de la mano de Velázquez, los italianos Mitelli y Colonna, siendo alojados en la Casa del Tesoro, comenzando su relación con el alcázar madrileño pintando al fresco los techos de diversas estancias pertenecientes al Cuarto Bajo de Verano del Rey; para con posterioridad iniciar la decoración del Salón de los Espejos, como afirma Palomino, al que sigue Cean Bermúdez.

"En este tiempo se consideró, lo que se había de pintar en el salón Grande, que tiene las ventanas sobre la puerta principal de Palacio; y habiendo hecho elección de la fábula de Pandora, hizo Diego Velázquez la planta del techo con las divisiones, y forma de las pinturas, y en cada cuadro escrita la historia, que se había de ejecutar. Comenzaron esta obra el año de 1659 por el mes de abril; tocóle a Don Juan Carreño el pintar a el fresco a el dios Júpiter, y a Vulcano su Herrero, (...). A Miguel Colona le toco pintar, cuando Júpiter mandó a los dioses, que cada uno la dotase de algún don, (...). A Don Francisco Rizi le tocó pintar a Júpiter, dándole a Pandora un riquísimo vaso de oro, (...). En otra parte pintó a Pandora ofreciéndole a Prometeo aquel vaso de oro, (...). A Mitelli le tocó el ornato, que hizo con tan gran manera, enriqueciéndolo con tan hermosa arquitectura, fundado, y macizo ornamento, que parece poner fuerza a al edificio; y lo que es muy digno de toda ponderación, la mucha facilidad, y destreza con que está obrado. (...)

Para todas estas historias se hicieron excelentes dibujos, o cartones del mismo tamaño en papel teñido, que servía de media tinta a el realce blanco; (...).» ${ }^{15}$

\footnotetext{
14 VARios aUtores: Palacios Reales en España, Visor /Argentaria, Madrid, 1986, pág. 60.

15 Antonio Palomino: El Museo Pictórico y Escala Óptica. El Parnaso Español Pintoresco Laureado, Aguilar, Madrid, 1988, t. III, pág. 252 y ss.

Agustín Cean Bermúdez: Diccionario Histórico de los más ilustres profesores de las Bellas Artes en España, Madrid, 1965, t. I, pág. 348 y ss.
} 


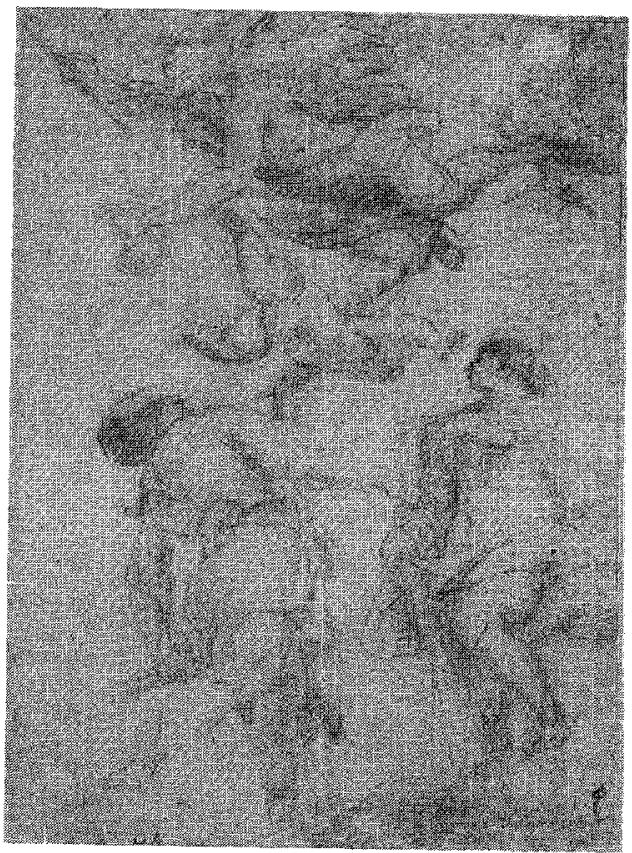

Fig. 8. Juan Carreño de Miranda. Mercurio, Epimeteo y Pandora. Lápiz negrc y sanguina. Real Academia de San Fernando, Madrid.

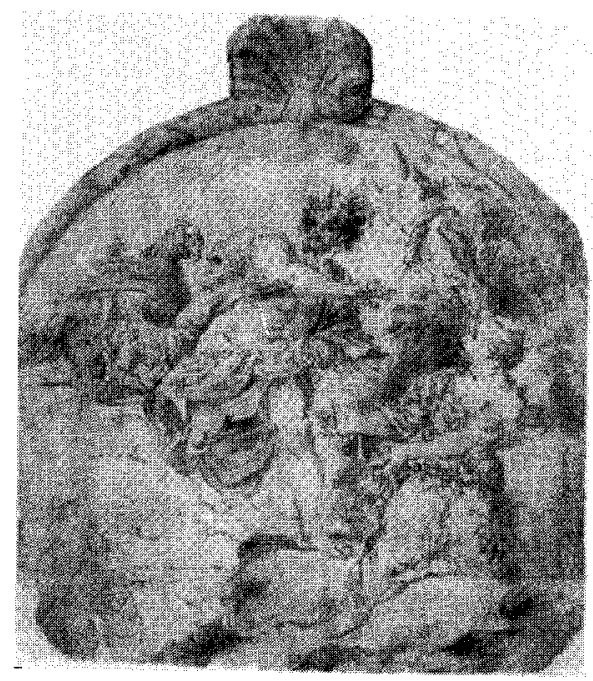

Fig. 9. Francisco Ricci. Júpiter entregando a Pandora el vaso de oro. Dibujo. Museo de San Pio V, Valencia. 
Toda esta decoración pictórica se perdió en el incendio del Alcázar, pudiendo sólo imaginárnosla por la descripción de Palomino y los pocos dibujos preparatorios que han llegado a nosotros, destacan dos dibujos de las historias mitológicas, uno de ellos de Carreño (ver Fig. 8), y el otro de Francisco Ricci (ver Fig. 9). Igualmente se conservan, en la Biblioteca Nacional de Madrid, unos dibujos de Mitelli y Colonna que algunos autores han relacionado con estos frescos ${ }^{16}$ (ver Fig. 10).

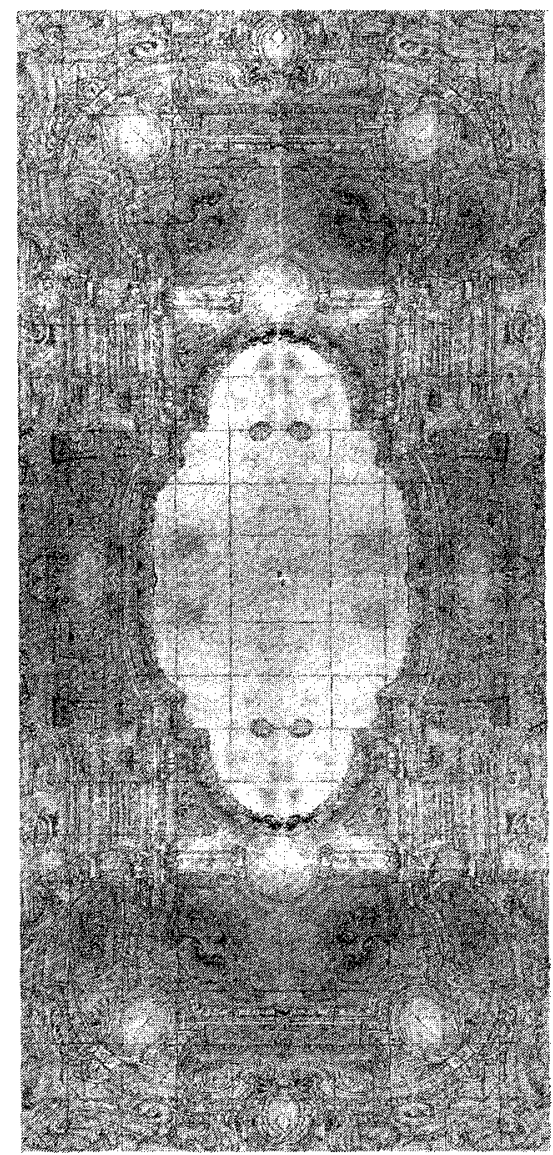

Fig. 10. Dibujos preparatorios para el Salón de los Espejos. Agostino Mitelli y Angelo Michele Colonna.

Decoración para una bóveda. Pluma, aguada sepia y toques de blanco. Biblioteca Nacional, Madrid.

16 Fernando Checa: El Real Alcázar de Madrid, Nerea/Comunidad de Madrid, Madrid, 1994. págs. 161 y 162. y José Manuel Barbeito: Alcázar de Madrid. Colegio Oficial de Arquitectos de Madrid, Madrid, 1992, pág. 174. 

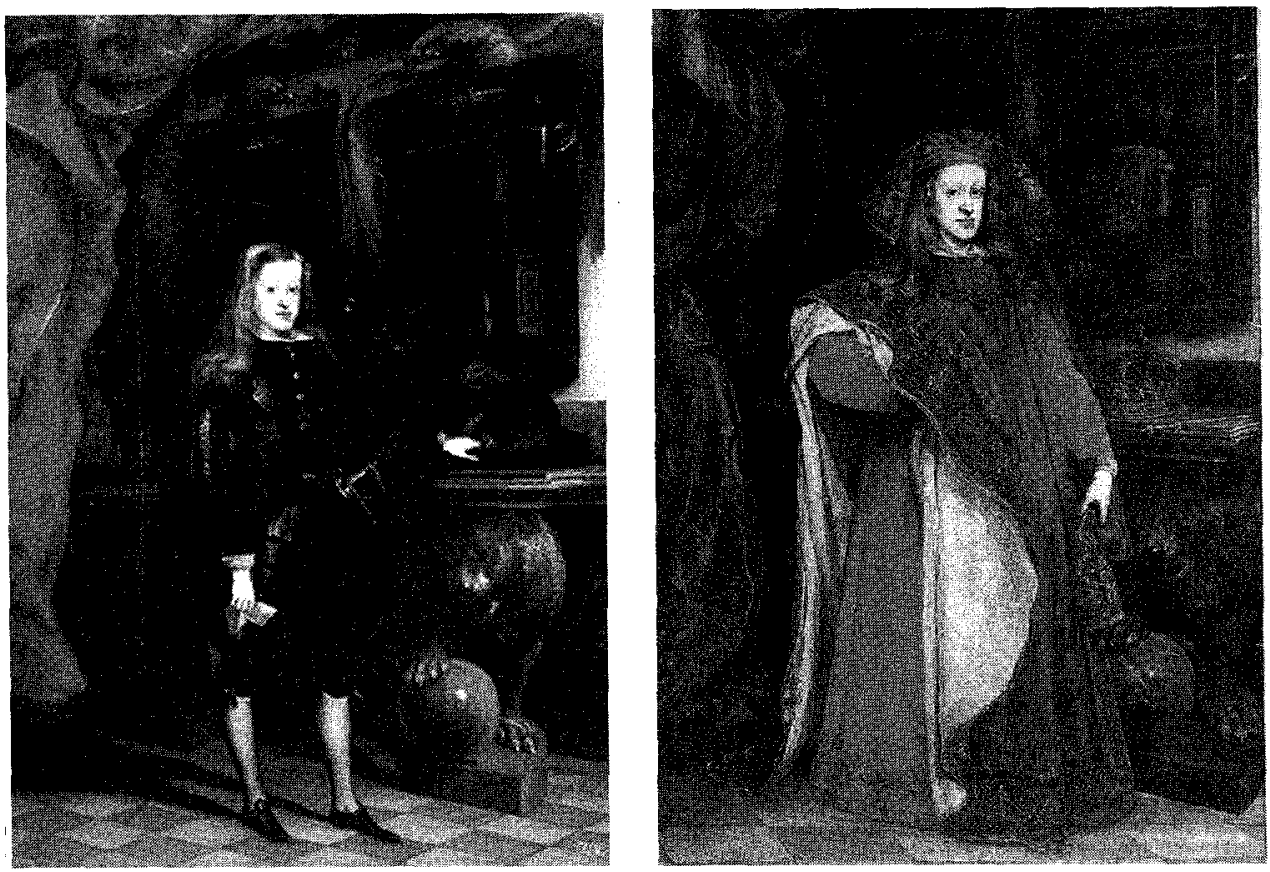

Fig. 11. Juan Carreño de Miranda.

Izq. Carlos II en el Salón de los Espejos.

Museo del Prado, Madrid.

Der. Carlos II como Gran Maestre de la Orden del Toisón de Oro.

Colección Harrach. Rohrau, Austria.

Hemos de dejar constancia de la camaradería, e incluso de la amistad, que unieron a todos los artistas que cooperaron en la decoración pictórica del Salón de los Espejos. Velázquez conocía bien, como hemos podido constatar, a los italianos Mitelli y Colonna, y su relación con Carreño y Ricci era estrecha, trato que, con el primero, era de evidente amistad, ya que éste figura entre los testigos que declararán a su favor en las pesquisas preliminares para la concesión del hábito de Santiago en $1658^{17}$. En cuanto a la elección de la temática mitológica habría partido, según lo expuesto por Palomino y aceptado por la historiografía, de Velázquez, que sería quien controlaría la realización de los frescos a nivel artístico, y evidentemente controlaría los gastos inherentes a esta obra, de ahí que aparezca su nombre en relación con la libranza motivo de este estudio. La realización de dichos

17 ARChivo Histórico NAcional: Informaciones de las calidades de Diego de Silva Velázquez. Varia Velazqueña, Ministerio de Educación Nacional, Madrid, 1960, t. II, pág. 329. 
frescos, según Palomino, se iniciaron en el mes de abril de 1659, y se concluirían en un breve tiempo, ya que la libranza de venta del andamiaje se fecha en 20 de Septiembre de ese mismo año; ello nos lleva a presuponer que los frescos sobre tema mitológico se habrían realizado con anterioridad, y serían los de temática arquitectónica y decorativa, que enmarcarían y realzarian los anteriores, los que se realizarían en 1659.

Es lástima que no exista una representación pictórica de los frescos que decoraban el regio salón; sólo aparece éste en unos pocos cuadros: algún retrato del rey Carlos II, y otros de la reina viuda y regente Mariana de Austria, obra de Carreño (Ver Fig. 11). En ellos se sitúan las regias figuras delante de una de las mesas soportada por leones, sobre la que cuelgan dos de los espejos que daban nombre a la estancia; y en ellos, y sobre ellos, se pueden atisbar los grandes lienzos que decoraban la estancia.

\section{RELACIÓN DE LAS OBRAS DE LA CAPILLA DE SAN ISIDRO CON LAS DE PALACIO}

La relación entre la fábrica de la Capilla de San Isidro y las obras de Palacio no parece que fueran muy fluidas siempre, existiendo constancia documental de diferencias y problemas entre ambas construcciones. Prueba de ello lo tenemos en el Libro de Acuerdos de la Capilla del Santo, donde aparece un acuerdo (ver Fig. 12) que se recha en 28 de Marzo de 1663, donde, entre otras medidas, la Junta para las obras y fabrica de la Capilla de San Isidro dispone lo siguiente:

"En Madrid, a veinte y ocho dias del mes de março de mil y seiscientos y sesenta y tres años...

Que por quanto muchos materiales que vienen para esta obra, de piedra, madera, cal y otros, con pretesto que son para palaçio se enbargan y detienen, se supplica y encarga al excelentisimo señor Duque de Medina de las Torres, comisario desta obra, cuyde que todos los materiales que constare ser para dicha obra, no se detengan ni enbarguen. (...)

Joseph Martinez. ${ }^{18}$

Los acuerdos que se tomaban en dicha reunión, irían encaminados a agilizar los diversos trabajos que se estaban llevando a cabo en la Capilla. Sería éste acuerdo un nuevo intento de «fiscalizar" y acelerar los trabajos pendientes de ejecución de la Capilla, y debió tener efecto, ya que en el Libro de Acuerdos no

18 Libro de Acuerdos de la Junta de la fabrica y obra de la Capilla de San Ysidro, Archivo Histórico Municipal de Madrid. Legajo 2-283-6, $f^{\circ} 49$ a $50 \mathrm{v}$. 

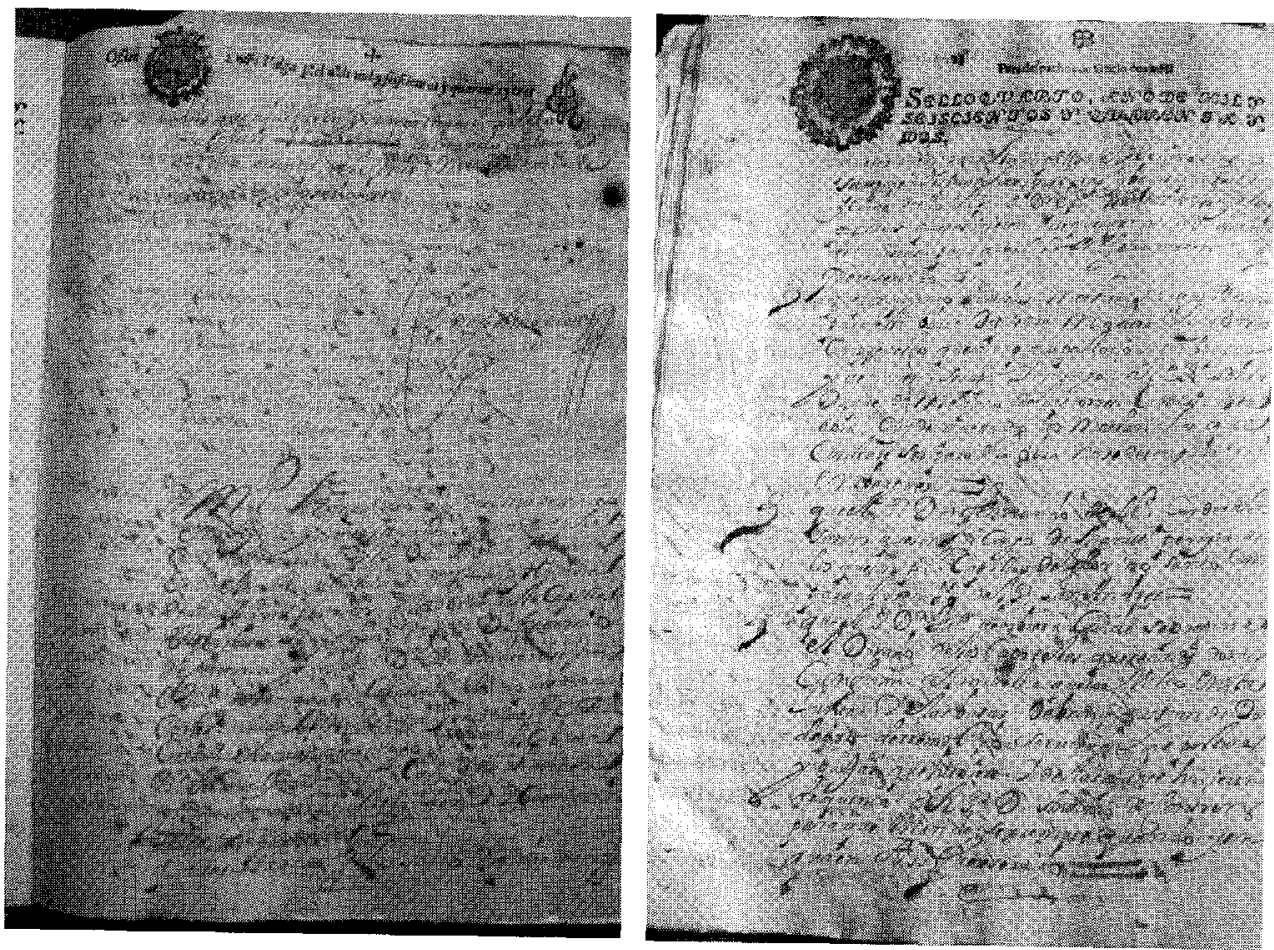

Fig. 12. Libro de Acuerdos. Legajo 2-283-6, fo 49 y $49 \mathrm{v}$. Archivo Histórico Municipal. Madrid.

aparece reflejada ninguna reunión más hasta Febrero de 1666; ello nos permite conjeturar que las obras se desarrollarían al ritmo deseado. Sin embargo, para nuestra intención, la cuestión que nos interesa serían las disputas que se intuyen existían entre los responsables de los trabajos que se estaban llevando a cabo en el alcázar madrileño, y los de la fábrica de San Isidro.

Tales enfrentamientos vendrian de antiguo, motivados por el desvio, hacia las obras reales, de los materiales que en un principio estaban destinos a las obras de la Capilla. Para tratar de subsanar el tema, como queda acordado, se solicitan los buenos oficios del duque de Medina de las Torres; su intervención parece que dio los resultados apetecidos, ya que no vuelven a reaparecer tales cuestiones en la abundante documentación relativa a la Capilla de San Isidro. Por tanto, constatamos con la documentación aportada, no sólo la relación de Velázquez con las obras de la Capilla del patrón de Madrid, también la existente entre ésta fábrica y las obras que se llevaban a cabo en el Real Alcázar. 


\section{FUENTES DOCUMENTALES}

Datta de las cantidades... Archivo Histórico Municipal de Madrid. Legajo 2-284-8/4a .

Libro de Acuerdos de la Junta de la fabrica y obra de la Capilla de San Ysidro. Archivo Histórico Municipal de Madrid. Legajo 2-283-6.

\section{BIBLIOGRAFIA}

ANTONIO, Trinidad de: El siglo XVII español, Historia del Arte, n. ${ }^{\circ} 31$. Historia 16, Madrid, 1989.

Alvar EzQuerra, Alfredo: El Nacimiento de una capital europea, Madrid entre 1561 y 1606, Turner/Ayuntamiento de Madrid, Madrid, 1989.

AzCARATE, José María de: Datos para las biografias de los arquitectos de la corte de Felipe $\mathrm{I}$, Revista de la Universidad de Madrid, 1962.

Barbeito, José Manuel: Alcázar de Madrid, Colegio Oficial de Arquitectos de Madrid, Madrid, 1992.

Brown, Dale: El Mundo de Velázquez, Time-Life, Barcelona, 1981.

CÁmARA, Alicia: «El Alcázar de Madrid, de castillo a palacio», Descubrir el Arte, n. ${ }^{\circ}$ 36, Madrid, 1992.

Cean Bermúdez, Agustín: Diccionario Histórico de los más ilustres profesores de las Bellas Artes en España, Madrid, 1965.

CHECA, Fernando: El Real Alcázar de Madrid, Nerea/Comunidad de Madrid, Madrid, 1994.

GAYA, Ramón: Velázquez, pájaro solitario, Biblioteca de la cultura andaluza, n. ${ }^{\circ}$, Granada, 1984.

HarRIS, Enriqueta: Velázquez, Universidad del País Vasco, Vitoria, 1991.

KaGAN, Richard L: Ciudades del siglo de Oro, Ediciones El Viso, Madrid, 1986.

MARÍAS, Fernando: Diego Velázquez, El arte y sus creadores, Historia 16, Madrid, 1993.

Palomino, Antonio: El Museo Pictórico y Escala Óptica. El Parnaso español Pintoresco Laureado, Aguilar, Madrid, 1988.

TOVAR MARTín, Virginia: Arquitectura madrileña del siglo XVII, Instituto de Estudios Madrileños, Madrid, 1983.

Tovar MaRTíN, Virginia: «El pintor Velázquez ¿decorador y arquitecto?» Revista de arte, geografia e historia, n. ${ }^{\circ}$ 2, Madrid, 1999.

VARIA VeLAZQUENAA: Ministerio de Educación Nacional, Madrid, 1960, t. I y t. II.

VARIOS AUTORES: El dibujo europeo en tiempo de Velázquez, Real Academia de Bellas Artes de San Fernando, Madrid, 1999.

VARIOS AUTORES: Dibujos de Arquitectura y ornamentación de la Biblioteca Nacional, siglos XVI y XVII. Ministerio de Cultura, Biblioteca Nacional, Madrid, 1991.

VARIOS AUTORES: Juan Gómez de Mora (1586-1648), Ayuntamiento de Madrid, Madrid, 1996.

VARIOS AUTORES: El Madrid de Velázquez y Calderón. Villa y Corte en el siglo XVil, Ayuntamiento de Madrid y Fundación Caja Madrid, Madrid, 2000.

VARIOS AUTORES: Palacios Reales en España, Visor/Argentaria, Madrid, 1990.

VARIOS AUTORES: Velázquez, Ministerio de Cultura, Madrid, 1996.

VelÁzQUez Y lo VelazQueño: Catálogo de la exposición homenaje a Diego de Silva Velázquez en el III centenario de su muerte (1660-1960), Ministerio de Educación Nacional, Madrid, 1960. 